 14tact

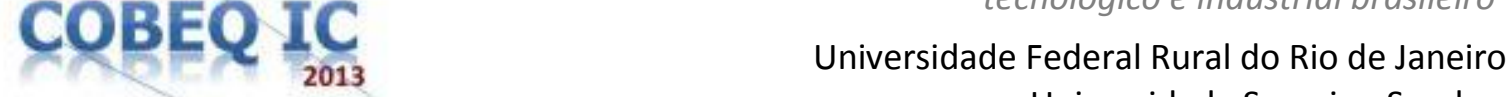 Universidade Severino Sombra Vassouras - RJ - Brasil
}

\section{OTIMIZAÇÃO DO TEMPO NA PRODUÇÃO DE LIPASE POR Candida rugosa EM MELAÇO DE SOJA}

\author{
I.M. V. BARBOSA ${ }^{1}$; W.G. MORAIS JR ${ }^{2}$ e V.L. CARDOSO ${ }^{3}$ \\ ${ }^{(1)}$ Bolsista de Iniciação Científica - PIBITI/CNPq/UFU; ${ }^{(2)}$ Doutorando - FEQ/UFU; ${ }^{(3)}$ Docente - \\ FEQ/UFU \\ Faculdade de Engenharia Química - Universidade Federal de Uberlândia - UFU, Av. João Naves de \\ Ávila, 2121, Campus Santa Mônica - Bloco 1K - Uberlândia, MG - CEP 38400-902 - e-mail: \\ vicelma@ufu.br
}

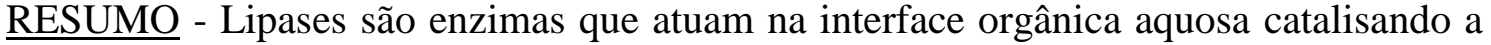
hidrólise das ligações éster-carboxilases presentes em acilgliceróis liberando ácidos orgânicos e glicerol, catalisando reações de esterificação, transesterificação ou interesterificação. A obtenção dessas enzimas é um processo caro devido aos altos custos na produção da lipase. Assim, visando diminuir estes custos, este trabalho tem como objetivo estudar a influência da concentração de melaço de soja (co-produto do processo de secagem da proteína de soja) na produção de lipase por Candida e otimizar o tempo de fermentação. Os testes para otimização do tempo de fermentação foram realizados em meio de cultura com pH 6 e concentração de melaço de soja de $200 \mathrm{~g} / \mathrm{L}$. A atividade de lipase foi determinada pelo método de titulação com $\mathrm{NaOH} 0,05 \mathrm{~N}$. Os resultados mostram que o melaço de soja é uma boa fonte de nutrientes na produção de lipase. A atividade lipolítica máxima de 5,25 U/mL foi alcançada em 12 horas de fermentação submersa. Após otimizar o tempo de produção, avaliou-se a influência da concentração de melaço de soja no meio para fermentação, obtendo-se os melhores resultados na concentração de $250 \mathrm{~g} / \mathrm{L}$.
\end{abstract}

Palavras chave: co-produto, fermentação submersa, influência.

\section{INTRODUÇÃO}

Enzimas são biocatalisadores com propriedades que as tornam altamente requisitadas. Por serem muito ativas e versáteis, realizam uma série de transformações de maneira seletiva e rápida. A grande vantagem das enzimas é que catalisam as transformações moleculares sem ocorrência de reações paralelas, o que ocorre comumente em sínteses químicas, devido à sua especificidade (Reed, 1975; Dziezak, 1991; Patel, 2002; Pizarro \& Park, 2003).

Triacilglicerol éster hidrolases (EC 3.1.1.3), nome sistemático das lipases, também conhecidas como hidrolases, são enzimas que realizam a catálise na hidrólise de triglicerídeos de cadeia longa. Elas atuam na interface orgânica aquosa catalisando a hidrólise das ligações éster carboxilases presentes em acilgliceróis liberando ácidos orgânicos e glicerol. Nestas condições, as lipases podem catalisar reações de 
esterificação, transesterificação

interesterificação (Freire et al., 1997).

As lipases são utilizadas no processamento industrial de gorduras e outros lipídeos e como aditivos em detergentes, sendo que atualmente podem ser encontradas em vários segmentos industriais. Há um grande potencial de aplicação dessas enzimas na área bioenergética, no processo de transesterificação enzimática de óleos e gorduras na presença de solventes para produção de biodiesel (Kontkanen et al., 2004).

Atualmente, as enzimas lipolíticas constituem o grupo mais importante de enzimas com enorme potencial para aplicações biotecnológicas, principalmente pelas lipases de origem microbiana, sendo estas as mais estudadas ultimamente. Isto se dá devido às características próprias destas enzimas, como a estabilidade a altas temperaturas, ampla faixa de atuação em relação ao $\mathrm{pH}$, além da sua seletividade na resolução de misturas racêmicas. No entanto, existem limitações para a utilização industrial da lipase microbiana, como o custo para a sua obtenção, que é determinado pelo rendimento da produção, pelas condições do processo e pela estabilidade da enzima (Hadeball, 1991; Sharma et al., 2001).

Para que tais limitações sejam solucionadas, alguns métodos têm sido comumente empregados para aumentar a produtividade do processo, um consiste na seleção do micro-organismo e otimização das condições de fermentação para aumentar a atividade lipásica; o outro consiste na redução do tempo de fermentação (Pinheiro, 2008).

As lipases podem ser produzidas através da fermentação submersa (FS) ou pela fermentação em estado sólido (FES). A FES baseia-se no crescimento e metabolismo dos micro-organismos em sólidos úmidos sem a presença de água livre e a FS é realizada em meio de cultura líquida, com nutrientes solúveis (Castilho et al., 2000).

Estão sendo desenvolvidos estudos envolvendo a utilização de micro-organismos e formas diferentes de produzi-los em meio de fermentação submersa, o mais utilizado industrialmente, na tentativa de se encontrar condições operacionais ideais para produção de lipases com maiores rendimentos.

Dentre os micro-organismos produtores de lipases estão os fungos filamentosos, os mais utilizados nos processos biotecnológicos, as bactérias e as leveduras.

Leveduras são fungos unicelulares capazes de reproduzir-se vegetativamente por brotamento das células ou, mais raramente, por fissão celular. Essa característica confere às leveduras a capacidade de multiplicar-se rapidamente em ambientes líquidos, que favorecem a dispersão das células (Pitt \& Hocking, 1999). Apenas alguns gêneros de leveduras sintetizam lipases, são elas: Candida, Saccharomyces, Saccharomycopsis, Yarrowia e Geotrichum. (Hadeball, 1991).

A síntese de lipase pelos microorganismos é influenciada por vários fatores, como por exemplo: fonte de carbono; fonte de nitrogênio; presença de indutores, presença de estimuladores e inibidores; presença de agentes que afetam a interface óleo/água; temperatura de incubação, $\mathrm{pH}$ do meio de cultura e inóculo (Hadeball, 1991; Obradors et al., 1993; Montesino et al., 1996; Dominguez et al., 2003).

Devido à especificidade das lipases e sua ampla aplicação tecnológica, verifica-se a necessidade de investigar maneiras economicamente viáveis de obtenção dessas enzimas, otimizando o processo produtivo das mesmas.

A partir destes aspectos, neste trabalho, realizou-se a otimização do tempo da produção de lipase por Candida rugosa, por fermentação submersa em meio contendo como substrato o melaço de soja (subproduto industrial provenientes de plantas de processamento de proteína isolada de soja), variando a concentração de melaço de soja.

\section{MATERIAIS E MÉTODOS}

\section{Materiais}

As cepas de Candida rugosa utilizadas, foram cedidas pela professora doutora Eliana Setsuko Kamimura da Faculdade de Zootecnia e Engenharia de Alimentos da USP. O melaço de soja foi obtido pela empresa processadora de soja Selecta, localizada em Araguari/MG. 
Composição do melaço de soja: O melaço de soja foi caracterizado por Romão et al. (2011). Os carboidratos, representando $60,8 \%$ da massa seca do melaço, incluem principalmente sacarose $(25,99 \%)$, estaquiose $(15,5 \%)$ e rafinose $(11,74 \%)$. O melaço também contém uma quantidade significativa de proteínas $(6,44 \%)$, lípidos $(15,6 \%)$, e cinzas $(7,88 \%)$.

Meio de manutenção dos micro-organismos

O meio de manutenção dos microorganismos foi em meio Saboraud, composto de $10 \mathrm{~g} / \mathrm{L}$ de peptona bacteriológica, $40 \mathrm{~g} / \mathrm{L}$ de dextrose e $20 \mathrm{~g} / \mathrm{L}$ de Agar. O micro-organismo foi incubado à $34^{\circ} \mathrm{C}$ por 48 horas e após este tempo, mantido a $5^{\circ} \mathrm{C}$ em refrigerador.

\section{Fermentação submersa}

O meio para fermentação submersa para otimização do tempo de produção de lipase foi preparado com uma concentração de 200 g/L de melaço de soja.

Os micro-organismos foram inoculados, separadamente, em erlenmeyers de $250 \mathrm{~mL}$ contendo $50 \mathrm{~mL}$ de meio e colocados sob agitação em incubadora rotativa a $130 \mathrm{rpm}$ e $25^{\circ} \mathrm{C}$ durante 120 horas. Durante este período avaliou-se o melhor tempo para a produção da lipase retirando amostras a cada 2 horas.

Para verificar a influência da concentração de melaço de soja no meio de fermentação, o melaço foi diluído para as concentrações de $100 \mathrm{~g} / \mathrm{L}, 150 \mathrm{~g} / \mathrm{L}, 200 \mathrm{~g} / \mathrm{L}$, $250 \mathrm{~g} / \mathrm{L}, 300 \mathrm{~g} / \mathrm{L}$ e $350 \mathrm{~g} / \mathrm{L}$.

\section{Determinação da atividade enzimática da lipase}

A atividade enzimática da lipase foi determinada por titulação com $\mathrm{NaOH} 0,05 \mathrm{~N}$, medindo a concentração de ácidos graxos livres. A reação foi realizada em erlenmeyers de $125 \mathrm{~mL}$ com $5 \mathrm{~mL}$ de emulsão composta de $25 \%$ azeite de oliva e $75 \%$ goma arábica $(7 \%$ $\mathrm{p} / \mathrm{v}$ ) como substrato, $2 \mathrm{~mL}$ de tampão fosfato de sódio $0,1 \mathrm{M}$ pH 7 e $1 \mathrm{~mL}$ do meio fermentado centrifugado.

Agitou-se a solução por 30 minutos a $45^{\circ} \mathrm{C}$ com ajuda de um agitador magnético. A reação foi interrompida adicionando-se $10 \mathrm{~mL}$ de solução acetona e etanol (1:1). Os ácidos graxos liberados durante a reação foram titulados na presença do indicador fenolftaleína.

A atividade foi expressa em unidades de lipase (U), correspondente à $1 \mu \mathrm{mol}$ de ácido graxo liberado por minuto nas condições especificadas.

\section{Determinação da atividade enzimática da protease}

A atividade enzimática da protease foi determinada reagindo $0,5 \mathrm{~mL}$ de azocaseína $1 \%$ e $0,3 \mathrm{~mL}$ de meio fermentado centrifugado. Após 1 hora de incubação a $37^{\circ} \mathrm{C}$ em um banho termostático, as amostras foram resfriadas em temperatura ambiente. Logo após, adicionou-se 2,4 $\mathrm{mL}$ de ácido tricloacético $10 \%$ e centrifugou-se a mistura a $3000 \mathrm{rpm}$ por 15 minutos. Adicionou-se 2,4 $\mathrm{mL}$ de $\mathrm{NaOH} 1 \mathrm{~N}$ em 1,6 mL do sobrenadante resultante, e a absorbância foi lida em espectrofotômetro a $440 \mathrm{~nm}$,

$A$ atividade foi expressa em unidade de protease (U), definida como a quantidade de enzima necessária para obter uma diferença de absorbância de 1 U/mL.min de meio fermentado contendo a enzima.

\section{Crescimento celular (Massa Seca)}

$\mathrm{O}$ crescimento celular foi quantificado realizando-se a massa seca. Após centrifugar o meio fermentado, lavou-se o centrifugado por 3 vezes com água destilada e, em placa de petri, colocou-se para secar em estufa à $90^{\circ} \mathrm{C}$ por 48 horas. Após o tempo decorrido colocou-se as placas com a massa seca em dessecador contendo sílica, por 2 horas, pesando as posteriormente. por litro.

A massa seca foi expressa em gramas

\section{RESULTADOS E DISCUSSÕES}

Os resultados obtidos a partir dos testes realizados a fim de otimizar o tempo da produção de lipase em melaço de soja são apresentados na Figura 1. 


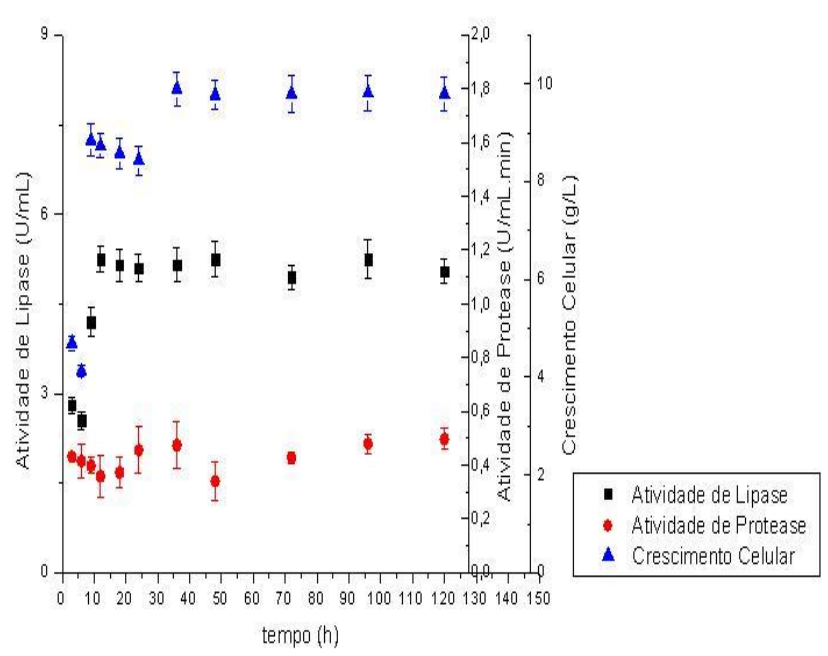

Figura 1 - Resultados das análises físicoquímicas realizadas com melaço de soja fermentado com Candida rugosa.

Observa-se que a atividade de lipase, no meio fermentado por Candida rugosa, aumenta até o tempo de 12 horas de fermentação, alcançando o valor de $5,3 \mathrm{U} / \mathrm{mL}$, a partir de 48 horas de fermentação, começa uma leve diminuição na sua atividade. Analisando os resultados da atividade de protease podemos concluir que seu aumento, após as 48 horas de fermentação, não influencia na diminuição da atividade de lipase. Os resultados de massa seca mostram que houve crescimento celular nas primeiras 36 horas de fermentação, quando se alcançou um valor de 9,9 g/L, a partir daí se manteve praticamente constante.

Para os testes realizados variando-se a concentração de melaço de soja no meio de fermentação, obteve-se uma melhor atividade de lipase de 6,3 U/mL, também para a concentração de $250 \mathrm{~g} / \mathrm{L}$ de melaço de soja, como mostra na Figura 2.

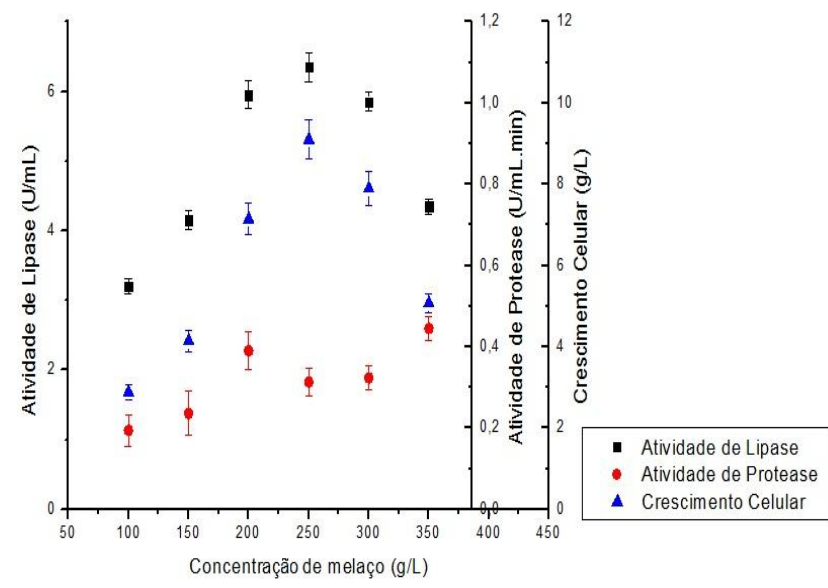

Figura 2 - Resultados das análises físicoquímicas realizadas com melaço de soja fermentado com Candida rugosa, variando a concentração.

As atividades de lipase observadas neste trabalho apresentam resultados promissores para produção de lipase microbiana a partir de melaço de soja em fermentação submersa. Os valores de atividade de lipase obtidos pela fermentação por Candida rugosa são superiores aos encontrados por Dalmau et al. (2000), que alcançaram uma máxima atividade de lipase no valor de 5,3 U/mL, com ácido pálmico como substrato, assim como Rajendran et al. (2008) que chegaram à um resultado máximo de atividade de lipase de 3,8 $\mathrm{U} / \mathrm{mL}$.

\section{CONCLUSÃO}

A partir dos resultados alcançados pelos ensaios realizados neste trabalho, foi possível concluir que o tempo ótimo encontrado, para produção de lipase em melaço de soja, foi de 12 horas, quando se obteve uma atividade de lipase máxima de $5,3 \mathrm{U} / \mathrm{mL}$, mantendo-se constante por mais 24 horas e decrescendo após esse tempo. Nesse caso, a atividade de protease não interferiu na atividade de lipase.

Em relação à concentração de melaço de soja, obteve-se em uma concentração de 250,0 g/L uma atividade de lípase ótima de 6,3 $\mathrm{U} / \mathrm{mL}$. 


\section{REFERÊNCIAS}

CASTILHO, L.R., FREIRE, D.M.G. 2000. Lipases produzidas por fermentação submersa e em meio sólido. Rev. Bras. Farm. 81(1/2), 48-56.

DALMAU, E., MONTESINOS, J. L., LOTTI, M., \& CASAS, C. - Effect of different carbon sources on lipase production by Candida rugosa. Enzyme and Microbial Technology, v. 26, p. 657-663, 2000.

DOMINGUEZ, A.; COSTAS, M.; LONGO, M.A.; SANROMÁN, A. A novel application of solid culture: production of lipases by Yarrowia lipolytica. Biotechnology Letters, v. 25, p. 12251229, 2003.

DZIEZAK, J.D. Enzymes: catalyses for food processes. Food technology., v. 45, p. 78-85, 1991.

FREIRE, D.M., TELES, E.M.F., BON, E.P.S., Sant Anna Jr., G.L. 1997a. Lipase production by Penicillium restrictum in a bench scale fermenter: Media composition, agitation and aeration. Appl. Biochem. Biotechnol. 63, 429-421.

HADEBALL, W. Production of lipase by Yarrowia lipolítica. Acta Biotechnology , v. 11, p. 159-167, 1991

KONTKANEN, H.; TENKANEN, M.; FAGERSTROM， R.;REINIKAINEN, T.Characterisation of steryl esterase activities in commercial lipase preparations.J. Biotechnol., v.108, p.51$59,2004$.

MONTESINOS, J.L.; OSBRADORS, N.; GORDILLO, M.A.; VALERO, F.; LAFUENTE, J.; SOLÀ, C. Effect of nitrogen sources in batch and continuous cultures to lipase production by Candida rugosa. Applied Biochemistry and Biotechnology, v. 59, p. 25-37, 1996.

OBRADORS N.; MONTESINOS, J.L.; VALERO, F.; LAFUENTE, F.J.; SOLÀ, C. Effects of different fatty acids in lipase production by Candida rugosa. Biotechnology letters. v. 15, p. 357-360, 1993.

PATEL, R.N. Microbial / enzymatic synt hesis of chiral intermediates for pharmaceuticals. Enz. Microbial Technol., v. 31, p. 804-826, 2002.

PINHEIRO, T. L. F.; LIPKE, N. R.; KEMPKA, A. P.; MENONCIN, S.; OLIVEIRA, D.; TREICHEL, H.; LUCCIO, M.; FREIRE, D. M. G. Response surface method to optimize the production and characterization of lipase from Penicillium verrucosum in solid state fermentation. Bioprocess and Biosystems Engineering, v. 31, n. 2, p. 119-125, 2008.

PITT, J.I.; HOCKING, A.D. Fungi and food spoilage. 2. ed. Maryland: Aspen, 1999. 593 p. PIZARRO, A.V.L.; PARK, E.Y. Lipase catalysed production of biodiesel fuel from vegetable oils contained in waste activated bleaching earth. Process Biochemistry, v.38, p. 1077-1082, 2003.

RAJENDRAN, A., PALANISAMY, A., \& THANGAVELU, V. - Evaluation of medium components by Plackett-Burman statistical design for lipase production by Candida rugosa and kinetic modeling. Chinese Journal of Biotechnology, v. 34, p. 436-444, 2008.

REED, G. Enzymes in food processing . 2. ed. Wisconsin: Academic Press, 1975. 573 p. RODRIGUES, M.I.; IEMMA, A.F. Planejamento de experimentos e otimização de processos. Campinas: Casa do Pão Editora. 2005. 326 p.

ROMÂO, B. B. Ethanol production from acidic hydrolysed of soybean molasses. Master dissertation, Federal University of Uberlândia, 2011.

SHARMA, R.; CHISTI, Y.; BANERJEE, U.C. Production, purification, characterization, and applications of lipases. Biotechnology Advances, v. 19, p. 627-662, 2001.

\section{AGRADECIMENTOS}

Os autores agradecem ao $\mathrm{CNPq}$, FAPEMIG e CAPES pelas bolsas vinculadas ao projeto. 